\title{
Interferon-free treatment of chronic hepatitis $C$ virus infection in patients with inherited bleeding disorders
}

\author{
Johannes Wiegand ${ }^{1}$; Ingolf Schiefke ${ }^{2,3} ;$ Kerstin Stein ${ }^{4}$; Thomas Berg' ${ }^{1}$; Ulrike Kullig ${ }^{5}$; \\ Katrin Ende ${ }^{6}$ \\ ${ }^{1}$ Klinik für Gastroenterologie und Rheumatologie, Sektion Hepatologie, Universität Leipzig, Germany; ${ }^{2}$ Praxis für \\ Gastroenterologie und Hepatologie Johannisplatz Leipzig, Germany; ${ }^{3} \mathrm{Klinik}$ für Gastroenterologie und Hepatologie, \\ Klinikum St. Georg gGmbH, Leipzig, Germany; ${ }^{4}$ Klinik für Gastroenterologie, Hepatologie und Infektiologie, Universität \\ Magdeburg, Germany; ${ }^{5}$ Krankenhaus Dresden-Friedrichstadt, 3. Medizinische Klinik, Dresden, Germany; \\ ${ }^{6}$ 2. Medizinische Klinik, Helios-Klinik Erfurt, Germany
}

\section{Keywords}

Sofosbuvir, ledipasvir, daclatasvir, simeprevir, paritaprevir

\section{Summary}

Chronic hepatitis C virus (HCV) infection causes significant mortality in patients with inherited bleeding disorders, however, data of interferon-free antiviral regimes are scarce in this population. Patients, methods: Reallife data of interferon-free therapies of $18 \mathrm{pa}$ tients with inherited bleeding disorders and chronic HCV genotype 1 infection (94\% male, liver cirrhosis Child $A / B n=4 / 1)$. Results: Treatment naïve patients were treated for eight weeks with sofosbuvir (SOF)/ledipasvir $(n=3)$ or for 12 weeks with SOF/ledipasvir $(n=4)$, SOF/ledipasvir/ribavirin $(n=1)$, or paritaprevir/r, ombitasvir, dasabuvir $(\mathrm{n}=$ 1). Treatment experienced patients without cirrhosis received SOF/ledipasvir $(n=3)$ or paritaprevir/r, ombitasvir, dasabuvir \pm ribavi-

Korrespondenzadresse

Johannes Wiegand

University of Leipzig, Department of Internal Medicine,

Dermatology, and Neurology, Clinic of Gastroentero-

logy and Rheumatology, Section of Hepatology

Liebigstr. 20, 04103 Leipzig, Germany

Tel. +49/(0)341/971 23-30, Fax -39

E-mail: johannes.wiegand@medizin.uni-leipzig.de in $(n=2)$ for 12 weeks. Re-treated cirrhotic individuals were treated for 24 weeks with SOF/ledipasvir $(\mathrm{n}=2)$ and SOF/daclatasvir ( $\mathrm{n}$ $=1$ ), or for 12 weeks SOF/simeprevir/1200 $\mathrm{mg} / \mathrm{d}$ ribavirin $(\mathrm{n}=1)$. Sustained virologic response (SVR-12) was achieved by $17 / 18$ individuals without severe on-treatment side effects. Conclusions: In real-life, HCV-infected patients with inherited bleeding disorders can be effectively and safely treated with interferon-free therapies.

\section{Schlüsselwörter}

Sofosbuvir, Ledipasvir, Daclatasvir, Simeprevir, Paritaprevir

\section{Zusammenfassung}

Eine chronische Hepatitis C Virusinfektion (HCV) ist für eine erhebliche Mortalität bei Patienten mit angeborenen Gerinnungsstörun-

Interferon-freie Behandlung der Hepatitis-CVirus-Infektion bei Patienten mit einer angeborenen Gerinnungsstörung

Hämostaseologie 2017; 37: 127-130

http://dx.doi.org/10.5482/HAMO-16-05-0014

received: May 17, 2016

accepted in revised form: July 4, 2016

epub ahead of print: July 15, 2016 gen verantwortlich, Erfahrungen zu modernen Interferon-freien Behandlungsoptionen liegen bisher jedoch kaum vor. Patienten, Methoden: Zusammenfassung von 18 "reallife" Interferon-freien Behandlungen bei Patienten mit angeborenen Gerinnungsstörungen und chronischer HCV Genotyp 1 Infektion ( $94 \%$ männlich, Leberzirrhose Child A/B n = 4/1). Ergebnisse: Naïve Patienten wurden für acht Wochen behandelt mit Sofosbuvir (SOF)/Ledipasvir ( $n=3$ ) oder für 12 Wochen mit SOF/Ledipasvir $(n=4)$, SOF/Ledipasvir/Ribavirin $(n=1)$, oder Paritaprevir/r, Ombitasvir, Dasabuvir $(n=1)$. Vorbehandelte Patienten ohne Zirrhose erhielten für 12 Wochen SOF/Ledipasvir ( $\mathrm{n}=3$ ) oder Paritaprevir/r, Ombitasvir, Dasabuvir \pm Ribavirin $(n=2)$. Vorbehandelte Patienten mit Zirrhose wurden für 24 Wochen mit SOF/Ledipasvir $(n=2)$ und SOF/Daclatasvir $(n=1)$ oder für 12 Wochen mit SOF/Simeprevir/1200 mg/d Ribavirin $(n=1)$ behandelt. Ein dauerhaftes virologisches Ansprechen (SVR-12) wurde bei 17/18 Patienten ohne schwerwiegende Nebenwirkungen erreicht. Schlussfolgerung: Patienten mit chronischer HCV-Infektion und angeborenen Gerinnungsstörungen können effektiv und sicher mit Interferon-freien Strategien behandelt werden.
Chronic hepatitis $\mathrm{C}$ virus (HCV) infection is a significant cause of morbidity and mortality in patients with inherited bleeding disorders and exposes them at risk for end stage liver disease, hepatic decompensation, hepatocellular carcinoma, and death (1-4). Treatment guidelines recommend that patients with hemophilia and chronic HCV infection should be treated with the available standard of care, which until recently consisted of peginterferon-based therapies (5). How- ever, large cohort data indicate that almost half of the patients did not receive antiviral therapy because of potential side effects, contraindications, or expectations for treatment approaches with direct antiviral agents (4). 


\begin{tabular}{|c|c|c|c|c|}
\hline \multicolumn{3}{|c|}{ characteristic } & $\mathbf{n}$ & $\%$ \\
\hline gender & \multicolumn{2}{|l|}{$\begin{array}{l}\text { male } \\
\text { female }\end{array}$} & $\begin{array}{r}17 \\
1\end{array}$ & $\begin{array}{r}94 \\
6\end{array}$ \\
\hline \multicolumn{3}{|c|}{ median body mass index $\left(\mathrm{kg} / \mathrm{m}^{2}\right)$} & \multicolumn{2}{|c|}{$25(21-31)$} \\
\hline $\begin{array}{l}\text { HCV } \\
\text { genotype }\end{array}$ & \multicolumn{2}{|l|}{$\begin{array}{l}1 \\
1 \mathrm{a} \\
1 \mathrm{~b}\end{array}$} & $\begin{array}{r}2 \\
2 \\
14\end{array}$ & $\begin{array}{l}11 \\
11 \\
78\end{array}$ \\
\hline \multicolumn{3}{|c|}{ median HCV-RNA at baseline (IU/ml) } & \multicolumn{2}{|c|}{$1.2 \times 10^{6}$} \\
\hline $\begin{array}{l}\text { liver } \\
\text { cirrhosis }\end{array}$ & \multicolumn{2}{|l|}{$\begin{array}{l}\text { Child A } \\
\text { Child B }\end{array}$} & $\begin{array}{l}4 \\
1\end{array}$ & $\begin{array}{r}22 \\
6\end{array}$ \\
\hline \multirow{3}{*}{$\begin{array}{l}\mathrm{HCV} \\
\text { treatment } \\
\text { status }\end{array}$} & \multicolumn{2}{|l|}{ naïve } & 9 & 50 \\
\hline & pre-treated & peginterferon/ribavirin & 5 & 28 \\
\hline & With & $\begin{array}{l}\text { peginterferon/ribavirin plus } \\
\text { telaprevir or boceprevir }\end{array}$ & 4 & 22 \\
\hline \multicolumn{3}{|c|}{$\begin{array}{l}\text { concomitant inherited bleeding disorder substitution } \\
\text { therapy }\end{array}$} & 6 & 33 \\
\hline
\end{tabular}

Tab. 1

Baseline characteristics of the study cohort.
The invention of interferon-free antiviral therapies with different combinations of protease-, polymerase-, and NS5A-inhibitors has revolutionized therapeutic options for all subgroups of patients with chronic HCV infection and has eliminated most of the concerns against peginterferon based therapies.

However, in patients with inherited bleeding disorders the experience is very limited so far. For the direct antiviral agents currently licensed in Europe, there is only one report with 14 patients who have been recruited in a subgroup of the sofosbuvir/ledipasvir study program. These individuals - all but one without evidence for cirrhosis - were treated for 12 weeks with sofosbuvir/ledipasvir in combination with weightbased ribavirin and achieved sustained virologic response in $100 \%$ of cases (6).

The aim of this study was to collect reallife data with different treatment regimens and treatment durations both in patients with and without cirrhosis.

\section{Patients, material, methods}

Clinical data of patients with chronic HCV monoinfection and inherited bleeding disorders were retrospectively collected by five German centres. Choice and duration of interferon-free antiviral regimens were ac- cording to the treating centre and within the label of the prescribed drugs (sofosbuvir/ledipasvir $400 \mathrm{mg} / 90 \mathrm{mg}$ once daily fixed-dose combination; sofosbuvir $400 \mathrm{mg}$ qd; simeprevir $150 \mathrm{mg}$ qd; daclatasvir 60 $\mathrm{mg}$ qd; paritaprevir/ritonavir/ombitasvir $75 \mathrm{mg} / 50 \mathrm{mg} / 12.5 \mathrm{mg} q \mathrm{~d}+$ dasabuvir 250 $\mathrm{mg}$ bid).

Sustained virologic response (SVR) was defined as undetectable HCV-RNA 12 weeks after the end of therapy (SVR-12). HCV-RNA was locally analyzed by one centre with the Abbott real-time PCR (Wiesbaden, Germany, lower limit of detection $12 \mathrm{IU} / \mathrm{ml}$ ) and by the other centers

Tab. 2 Adverse events of interferon-free antiviral treatment regimens.

\begin{tabular}{ll|l}
\hline adverse event & \multicolumn{2}{l}{ severity $(\mathrm{n})$} \\
\cline { 2 - 3 } & mild & moderate \\
\hline headache & $4(22 \%)$ & $1(6 \%)$ \\
\hline fatigue & $2(11 \%)$ & 0 \\
\hline pruritus & $2(11 \%)$ & 0 \\
\hline $\begin{array}{l}\text { exanthema } \\
\text { anemia }\end{array}$ & $1(6 \%)$ & 0 \\
\hline $\begin{array}{l}\text { nose or gingiva } \\
\text { bleeding }\end{array}$ & $1(6 \%)$ & $1(6 \%)$ \\
\hline $\begin{array}{l}\text { uncharacteristic } \\
\text { body ache }\end{array}$ & $1(6 \%)$ & 0 \\
\hline $\begin{array}{l}\text { bowel movement } \\
\text { irregularities }\end{array}$ & $1(6 \%)$ & 0 \\
\hline
\end{tabular}

with the Roche Cobas TaqMan assay (Mannheim, Germany, lower limit of detection $15 \mathrm{IU} / \mathrm{ml}$ ).

The study was approved by the Ethics Committee of the University of Leipzig (vote number 403-15-16112015).

\section{Results}

\section{Patient characteristics}

Eighteen Caucasian patients with inherited bleeding disorders were recruited:

- haemophilia A $\mathrm{n}=14$,

- haemophilia B n=3,

- factor XIII deficiency $n=1$.

They were either treatment naïve, pretreated with peginterferon/ribavirin, or with peginterferon/ribavirin plus telaprevir or boceprevir in nine, five, and four cases, respectively. Liver cirrhosis was present in five individuals:

- Child A $n=4$,

- Child B n = 1.

Further baseline characteristics are summarized ( Tab. 1).

\section{Treatment}

Naïve patients were treated for eight weeks with sofosbuvir/ledipasvir $(n=3)$ or for 12 weeks with sofosbuvir/ledipasvir ( $\mathrm{n}=4$, including the Child B cirrhotic patient), sofosbuvir/ledipasvir/800 $\mathrm{mg} / \mathrm{d}$ ribavirin $(\mathrm{n}=1)$, or paritaprevir/r, ombitasvir, dasabuvir $(\mathrm{n}=1)$, respectively.

Treatment experienced patients without cirrhosis achieved sofosbuvir/ledipasvir $(\mathrm{n}=3)$ or paritaprevir/r, ombitasvir, dasabuvir \pm RBV $(n=2)$ for 12 weeks.

Re-treated cirrhotic individuals were treated for 24 weeks with sofosbuvir/ledipasvir $(\mathrm{n}=2)$ and sofosbuvir/daclatasvir (n $=1$ ), or for 12 weeks with sofosbuvir/simeprevir/1200 mg/d ribavirin $(\mathrm{n}=1)$. Ribavirin was stopped due to anemia after four weeks in the latter patient.

Sustained virologic response (SVR-12) was achieved by $17 / 18$ individuals ( $94 \%$ ). The Child B cirrhotic patient was HCVRNA negative at the end of treatment and died four weeks later due to esophageal bleeding. 


\section{Safety and tolerability}

Clinically relevant on-treatment side effects were not observed in nine patients. In the remaining nine patients adverse events were mild or moderate ( $\$$ Tab. 2). Headache was most frequently reported. Mild nose and gingiva bleeding occurred in the Child B cirrhotic individual. Exanthema and anemia were related to ribavirin containing treatment regimens.

In the follow-up period of the treatment-naïve patient who received paritaprevir/r, ombitasvir, and dasabuvir spontaneous intracerebral hemorrhage occurred nine weeks after cessation of antiviral therapy. This patient was not on regular factor IX substitution therapy. The event was judged to be unrelated to the antiviral therapy.

\section{Discussion}

Published treatment experience with currently in Europe licensed interferon-free antiviral therapies for chronic HCV infection in patients with inherited bleeding disorders is so far limited to 14 cases who have all been treated with sofosbuvir, ledipasvir, and ribavirin in a clinical study program (6). Our study adds important real-life data and reports results with different antiviral regimens in treatment-naïve and in pretreated individuals with or without liver cirrhosis. Efficacy, safety, and tolerability are not significantly different from registration studies of interferon-free treatment regimens (7-10) and indicate that patients with chronic HCV infection and inherited bleeding disorders do not have to be considered as "special cohort" or "difficult to treat" in the real-life setting. This is important as the majority of these individuals has a long duration of $\mathrm{HCV}$ infection, is an ageing population at risk for liver cirrhosis and hepatocellular carcinoma, and may have had concerns against peginterferon based treatment regimens in the past.

Treatment duration for naïve patients without cirrhosis and a baseline HCV-RNA $<6 \mathrm{Mio}$. IU/mL can be shortened to eight instead of 12 weeks without compromising efficacy. Especially females with these characteristics qualify for the shorter treatment duration (7). However, treating physicians may not trust in the shorter treatment duration even if positive predictive baseline characteristics are fulfilled (11). In our cohort, eight cases with favourable baseline values qualified for eight weeks therapy with sofosbuvir/ledipasvir, however, 12 weeks regimens were preferred in five of these individuals, potentially because all of these cases were male. Currently in Europe available 12 weeks treatment options will soon be complemented by the combination grazoprevir/elbasvir which has been evaluated in a clinical study program specifically designed for patients with inherited blood disorders (12).

\section{Conclusion}

Our data show that patients with inherited bleeding disorders and chronic HCV genotype 1 infection can be effectively treated with interferon-free therapies in the reallife setting without severe side effects.

\section{Authorship contributions}

Data acquisition and preparation of manuscript: JW, IS, KS, TB, UK, KE; data analysis: JW, IS, KS, TB, UK, KE; preparation of ethical vote: JW.

\section{Conflict of interest}

JW has served as a speaker, a consultant, and an advisory board member for AbbVie, BMS, Boehringer, Gilead, Janssen, Roche, and Siemens, and has received research funding from Siemens and GlaxoSmithKline.

IS has received unrestricted research grants from MSD, Jansen, AbbVie, Takeda, and Gilead, and served as a consultant/advisory board member for Shire, Baxter, Dr. Falk Pharma, AbbVie, Fresenius, Intercept Pharma. He served as a speaker for Shire, Baxter, Dr. Falk Pharma, AbbVie, and Fresenius.

KS has served as speaker or advisory board member for AbbVie, BMS, Gilead, and Janssen.

TB has served as a speaker, a consultant, and an advisory board member for AbbVie, BMS, Boehringer, Gilead, Janssen,
Merck, Novartis, Roche, and Vertex Pharmaceuticals Incorporated, and has received research funding from Gilead, Janssen, Novartis, and Roche.

UK has served as a speaker and an advisory board member for AbbVie, BMS, Gilead, Janssen, and Roche.

KE has nothing to disclose.

\section{References}

1. Krebs H, Spannagl M, Schramm W. Morbidity and mortality of patients with haemophilia in Germany 2007/2008. Hämostaseologie 2009; 29 (Suppl 1): S7-S12.

2. Khan MM, Tait RC, Kerr R et al. Hepatitis C infection and outcomes in the Scottish haemophilia population. Haemophilia 2013; 19: 870-875.

3. Tagliaferri A, Rivolta GF, Iorio A et al. Mortality and causes of death in Italian persons with haemophilia, 1990-2007. Haemophilia 2010; 16: 437-446.

4. Fransen van de Putte DE, Makris M, Fischer K et al. Long-term follow-up of hepatitis $\mathrm{C}$ infection in a large cohort of patients with inherited bleeding disorders. J Hepatol 2014; 60: 39-45.

5. Zoulim F, Bailly F. New approaches to the management of hepatitis C in haemophilia in 2012. Haemophilia 2012; 18 (Suppl 4): 28-33.

6. Stedman CA, Hyland RH, Ding X et al. Once daily ledipasvir/sofosbuvir fixed-dose combination with ribavirin in patients with inherited bleeding disorders and hepatitis $\mathrm{C}$ genotype 1 infection. Haemophilia 2015; doi: 10.1111/hae.12791.

7. Kowdley KV, Gordon SC, Reddy KR et al. Ledipasvir and Sofosbuvir for 8 or 12 Weeks for Chronic HCV without Cirrhosis. N Engl J Med 2014; 370: 1879-1888.

8. Feld JJ, Kowdley KV, Coakley E et al. Treatment of HCV with ABT-450/r-Ombitasvir and Dasabuvir with Ribavirin. N Engl J Med 2014; 370: 1594-1603.

9. Sulkowski MS, Gardiner DF, Rodriguez-Torres M et al. Daclatasvir plus sofosbuvir for previously treated or untreated chronic HCV infection. N Engl J Med 2014; 370: 211-221.

10. Lawitz E, Sulkowski MS, Ghalib R et al. Simeprevir plus sofosbuvir, with or without ribavirin, to treat chronic infection with hepatitis $\mathrm{C}$ virus genotype 1 in non-responders to pegylated interferon and ribavirin and treatment-naive patients: the COSMOS randomised study. Lancet 2014; 384: 1756-1765.

11. Terrault N, Zeuzem S, DiBisceglie A et al. Treatment outcomes with 8,12 and 24 weeks regimens of ledipasvir/sofosbuvir for the treatment of hepatitis C infection: Analysis of a multicenter prospective observational study. Hepatology 2015; 61 (S1): 256A.

12. Hezode C, Colombo M, Spengler U et al. C-EDGE IBLD: Efficacy and safety of elbasvir/grazoprevir (EBR/GZR) in subjects with chronic hepatitis C virus infection and inherited blood disorders. J Hepatol 2016; 64: S753. 